\title{
Identification of regulatory elements flanking human XIST reveals species differences
}

\author{
Samuel C Chang, Carolyn J Brown ${ }^{*}$
}

\begin{abstract}
Background: The transcriptional silencing of one $X$ chromosome in eutherians requires transcription of the long non-coding RNA gene, XIST. Many regulatory elements have been identified downstream of the mouse Xist gene, including the antisense Tsix gene. However, these elements do not show sequence conservation with humans, and the human TSIX gene shows critical differences from the mouse. Thus we have undertaken an unbiased identification of regulatory elements both downstream and upstream of the human XIST gene using DNase I hypersensitivity mapping.

Results: Downstream of XIST a single DNase I hypersensitive site was identified in a mouse undifferentiated ES cell line containing an integration of the human XIC region. This site was not observed in somatic cells. Upstream of XIST, the distance to the flanking JPX gene is expanded in humans relative to mice, and we observe a hypersensitive site $65 \mathrm{~kb}$ upstream of XIST, in addition to hypersensitive sites near the XIST promoter. This -65 region has bi-directional promoter activity and shows sequence conservation in non-rodent eutheria.

Conclusions: The lack of regulatory elements corresponding to human TSIX lends further support to the argument that TSIX is not a regulator of XIST in humans. The upstream hypersensitive sites we identify show sequence conservation with other eutheria, but not with mice. Therefore the regulation of XIST seems to be different between mice and man, and regulatory sequences upstream of XIST may be important regulators of XIST in nonrodent eutheria instead of Tsix which is critical for Xist regulation in rodents.
\end{abstract}

\section{Background}

$\mathrm{X}$-chromosome inactivation results in transcriptional silencing of one of the two $\mathrm{X}$ chromosomes in female mammals, thereby ensuring dosage equivalence of most $\mathrm{X}$-linked genes between males and females. The $\mathrm{X}$ inactivation centre $(X I C)$ is a single locus on the $\mathrm{X}$ chromosome that is required in cis for $\mathrm{X}$-chromosome inactivation [1]. The XIC contains the X Inactive Specific Transcript (XIST/Xist) gene that produces a large (approximately $17 \mathrm{~kb}$ ) noncoding RNA [2-4] that is necessary and sufficient to induce $\mathrm{X}$ inactivation [5-7]. $\mathrm{X}$ inactivation occurs very early in mammalian development, making analysis of the initial events challenging, particularly in humans. Most analyses have therefore been done in mouse, where ES cells not only provide the ability to generate targeted mutations, but also

\footnotetext{
* Correspondence: cbrown@interchange.ubc.ca Department of Medical Genetics, Molecular Epigenetics Group, Life Sciences Institute, University of British Columbia 2350 Health Sciences Mall, Vancouver BC V6T 1Z3, Canada
}

(c) 2010 Chang and Brown; licensee BioMed Central Ltd. This is an Open Access article distributed under the terms of the Creative Commons Attribution License (http://creativecommons.org/licenses/by/2.0), which permits unrestricted use, distribution, and reproduction in any medium, provided the original work is properly cited. provide an in vitro system modelling $\mathrm{X}$ inactivation, as female ES cells undergo random $\mathrm{X}$ inactivation upon differentiation [8]. Detailed analyses of the genomic region downstream of the mouse Xist locus have revealed several cis-acting regulatory elements for Xist (see Figure 1A), including Tsix [9], DXPas34 and Xite [10].

The Tsix gene encodes an untranslated RNA antisense to Xist that is transcribed across the Xist locus, extending beyond the promoter of the sense strand $[9,11]$. A critical role for Tsix in regulating Xist expression was demonstrated by augmented Tsix expression resulting in inhibition of Xist accumulation [12] while deletion of the Tsix promoter resulted in primary non-random inactivation of the mutant X in females [13]. DXPas34, a $1.2 \mathrm{~kb}$ CG-rich region located $750 \mathrm{bp}$ downstream of the Tsix major promoter, is critical for Xist and Tsix regulation, and shows bi-directional promoter activity $[14,15]$. Xite, named as the X-inactivation intergenic transcription element, was identified by DNase I 


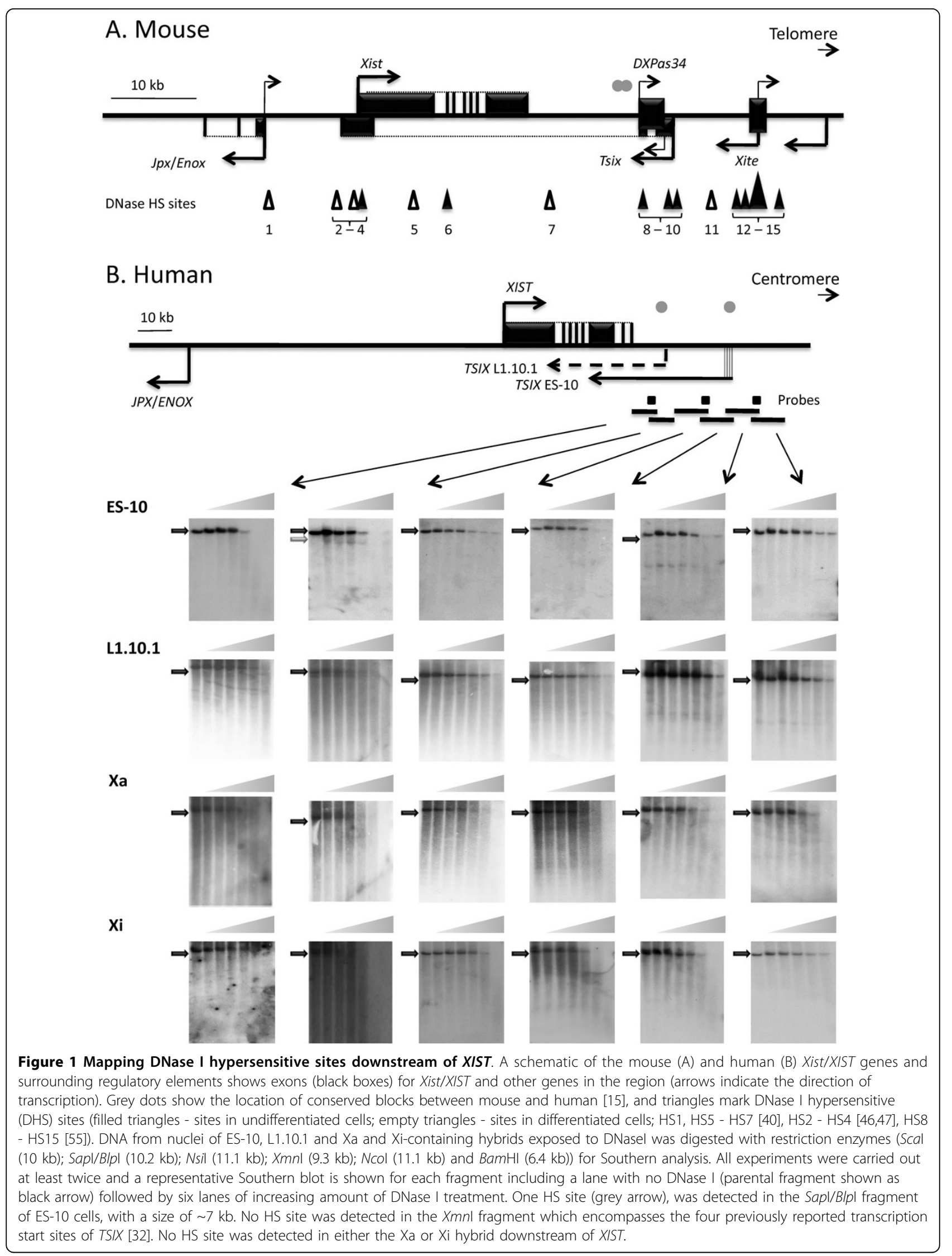


hypersensitive mapping, and is also a site of bi-directional transcription, although the transcripts themselves are not necessary for Xite to promote Tsix persistence on the active $\mathrm{X}$ [10]. Homologous pairing of a region downstream of Xist, encompassing Tsix, DXPas34 and Xite, is necessary for the initiation of $\mathrm{X}$ inactivation $[16,17]$. This pairing can be recapitulated by subfragments which contain a high density of CTCF sites, and CTCF as well as transcription is essential for the establishment of pairing [16].

While the mouse system provides an excellent framework from which we can understand the process of $\mathrm{X}$ inactivation, how human fits into this framework is not clear. XIST and Xist share sequence homology [3,4] and are each sufficient to initiate silencing $[18,19]$; however, there are substantial differences between the two species in other aspects of X-chromosome inactivation. Significantly, $\mathrm{X}$ inactivation is imprinted in mouse extraembryonic tissues [20] but not in humans (reviewed in [21]) and Tsix is very different from TSIX in patterns of expression and extent of transcription across the sense strand [22-24]. Human TSIX has been observed in embryoid bodies and a human embryonal carcinoma cell line, but also in chorionic villus cells [22,24]. TSIX is also expressed in mouse ES-10 cells carrying a multicopy integration of a $480 \mathrm{~kb}$ XIST-containing human YAC transgene [25] and in L1.10.1, a clone of a somatic male cell line transfected with a human XIST-containing PAC, which contains at least $50 \mathrm{~kb}$ of flanking genomic DNA [26]. While these cells did not show identical initiation sites for the TSIX transcript, in all cases the TSIX transcript truncated well before the 5' end of XIST. As human ES cells have been variable in their X inactivation status (e.g. [27]), mouse ES cells with a human transgene remain one of the best models for human $\mathrm{X}$ inactivation. Multi-copy integrations of the 480-kb transgene containing human XIST display partial $\mathrm{X}$ inactivation center function upon in vitro differentiation of male mouse embryonic stem cells, including activation in some cells of the endogenous mouse Xist locus $[28,29]$.

Given the importance of XIST for X inactivation, it is perhaps surprising that the $\mathrm{X}$ inactivation center region shows little sequence conservation surrounding XIST between mouse and human [30,31]. In addition to XIST, the region contains several conserved genes and a number of non-coding RNAs and pseudogenes. Downstream of Xist the closest gene is the testes-specific Ts $x$ gene in mouse, however TSX is a pseudogene in human [32]. The closest gene upstream of XIST is the JPX (also known as $E N O X$ ) non-coding RNA gene. Interestingly, the region between JPX and XIST is $\sim 90 \mathrm{~kb}$ in human, which is approximately 9 times larger than that of mouse. Thus rearrangements downstream of XIST where the mouse regulatory elements are found may have been compensated for by regulatory regions upstream of the gene. To identify such regulatory elements in the absence of substantial sequence conservation we have used DNase I hypersensitive site mapping as an unbiased approach to identify cis-acting regulatory elements in humans. Genomic regions hypersensitive to DNase I digestion (DHS sites) have been shown to harbour cis-regulatory elements critical for gene regulation [33], and both of the mouse Xist regulatory regions DXPas34 and Xite show DNase I hypersensitivity [12]. Here, we report the identification of three previously unknown hypersensitive sites surrounding the human XIST locus.

\section{Results}

Identification of DHS sites $3^{\prime}$ to human XIST

The critical timing for XIST regulation is early in development and thus for mapping of DHS sites 3' to human $X I S T$ we used the mouse undifferentiated embryonic stem cell line ES-10 which contains a human XIST transgene. We also examined the L1.10.1 cell line which is a somatic male HT1080 cell line transfected with a PAC containing the XIST region, and which expresses $X I S T$ as well as TSIX. Additionally, we examined mouse/human somatic cell hybrids containing either the human active (Xa) or inactive (Xi) chromosome, which provide a unique opportunity to compare the chromatin structure between the $\mathrm{Xi}$ and $\mathrm{Xa}$ independent of each other without requiring allele-specific detection. We generated three probes downstream of XIST that were able to detect six overlapping restriction fragments allowing the analysis of a $43 \mathrm{~kb}$ region (see Figure 1B). Only one DHS site, located approximately $12-13 \mathrm{~kb}$ downstream of XIST, was identified in the ES-10 cells. This DHS site does not correspond to the cluster of four TSIX transcription start sites described in these cells, which are located approximately $14 \mathrm{~kb}$ further from the 3' end of XIST [25]. The DHS site is close to the antisense transcription start in L1.10.1 cells. Interestingly, however, the DHS site was not found in L1.10.1 (Figure 1B), nor were any others, despite previous detection of antisense transcript both with $\mathrm{RT}$ PCR and FISH in this cell line [24]. We confirmed the ongoing presence of antisense transcript in the L1.10.1 cells used for DHS mapping by RT-PCR (data not shown). DHS mapping in both Xi and Xa hybrids did not show the presence of any DHS site downstream of $X I S T$, including at the region identified to contain a DHS in ES-10 cells (Figure 1B). It thus appears that, unlike the situation in mouse where there are both developmental-specific and constitutive DHS sites downstream of Xist, in humans there is only a single developmental-specific DHS site downstream of XIST. 
Identification of DHS sites $\mathbf{5}^{\prime}$ to human XIST

The lack of putative regulatory elements 3' to XIST, where many of the mouse transcriptional regulatory sites are located, led us to examine the region $5^{\prime}$ to XIST which is larger in humans than it is in mouse [30]. We generated three probes to examine the region upstream of human XIST for DHS sites. Almost $80 \%$ of the just over $90 \mathrm{~kb}$ region upstream of XIST is comprised of repetitive elements, predominantly LINE1 (39.5\%) and ALU (27.3\%) as identified by repeatmasker (http://www.repeatmasker.org/[34]). This high repeat content precluded examination of the entire region and the restriction fragments assessed by the three probes interrogate a total of $39 \mathrm{~kb}$ in the $90 \mathrm{~kb}$ region.

We again performed Southern analysis with DNA isolated after increasing DNase I treatment from cells of ES-10, an Xa-containing, and an Xi-containing somatic cell hybrid (Figure 2). The presence of multiple bands for proximal but not distal probes in ES-10 can be explained by the individual copies of the XIST transgene present in the multi-copy integration transgenes not containing the same amount of DNA sequence flanking the XIST locus. We observed one or more DHS site(s) immediately upstream of XIST in ES-10, as well as in the Xa-containing hybrid where XIST is silenced. These sites were observed variably in Xi-containing hybrids where XIST continues to be expressed (Figure 2). While no other hypersensitive sites were detected upstream of XIST in ES-10, one DHS site was found approximately $65 \mathrm{~kb}$ upstream of the XIST transcription start on both the active and inactive $\mathrm{X}$ chromosomes in somatic hybrids (Figure 2).

The location of the -65 DHS site was refined by repeating the DHS mapping with two other restriction enzyme digests for the Xa-containing hybrid (Figure $3 \mathrm{~A})$, thereby refining the location of the site to between $73,053,323$ and 73,053,866 (hg18). A dot-plot sequence comparison of human to cow, and human to mouse sequences showed that within the region approximately $60 \mathrm{~kb}$ upstream of XIST there is a region of

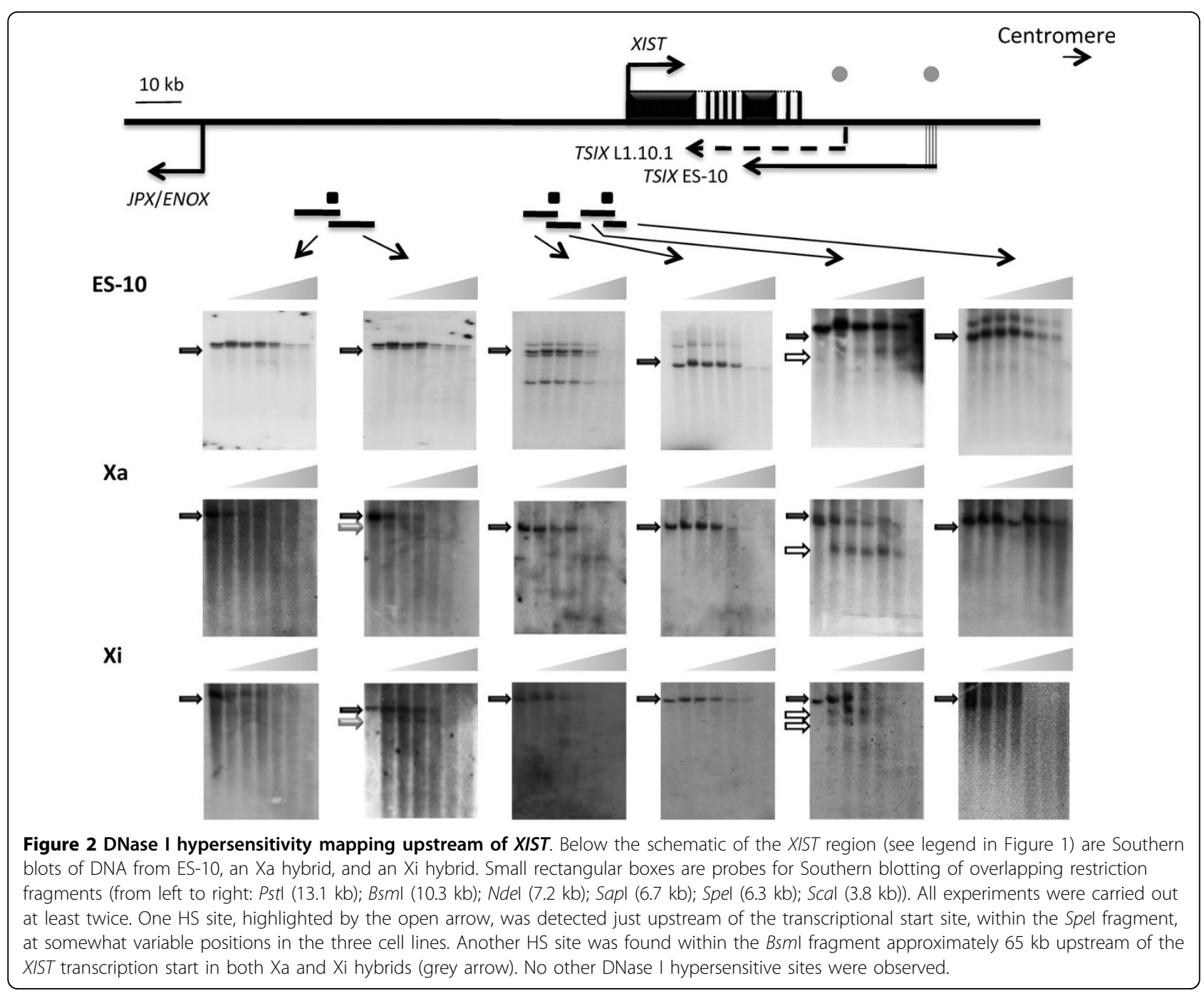


A

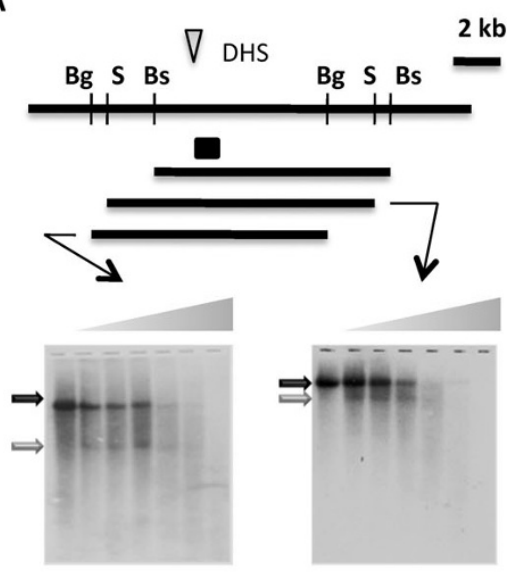

B

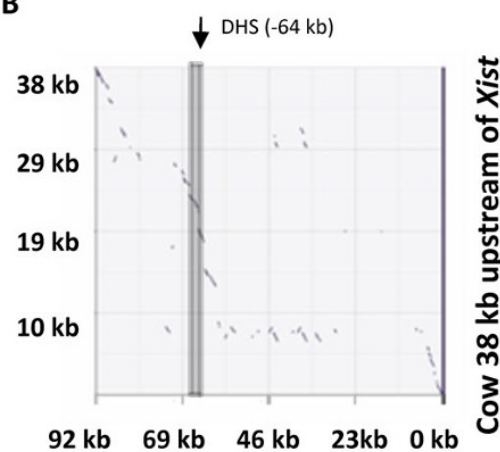

Human 91.6 kb upstream of Xist

C

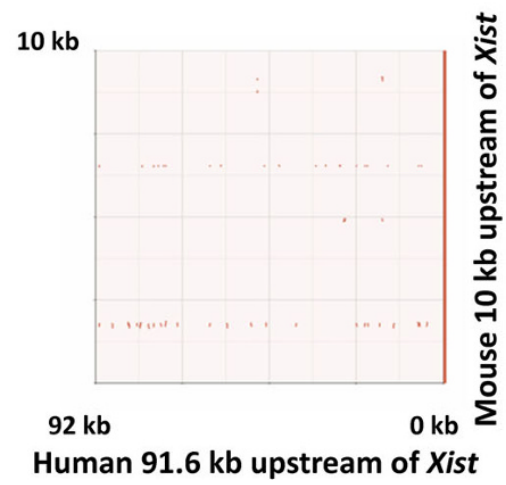

Figure 3 Localization of the -65 DNase I hypersensitive site upstream of XIST. A. Using an Xa hybrid to limit background from cross-hybridization to human material, two additional restriction digests were performed on different DNA preparations after increasing DNase I treatments to refine the location of the -65 site. The Bglll fragment is $9.3 \mathrm{~kb}$ and the fragment resulting from $\mathrm{HS}$ and restriction digestion is $5 \mathrm{~kb}$ (grey arrow, left panel). The Scal fragment is $11.8 \mathrm{~kb}$ and the fragment resulting from $\mathrm{HS}$ and restriction digestion is $8 \mathrm{~kb}$ (grey arrow, right panel). Dot-plot analyses http://mulan.dcode.org/ showing comparison of sequence upstream of XIST between cow (38 kb) and human (92 kb) (panel B) and mouse $(10 \mathrm{~kb})$ and human $(92 \mathrm{~kb})$ (panel C). approximately $10 \mathrm{~kb}$ that is relatively conserved between human and cow, but not mouse (Figure $3 \mathrm{~B}$ and $3 \mathrm{C}$ ). This region is also conserved in dog (data not shown). The novel -65 DHS site identified with both the Xa and $\mathrm{Xi}$ in somatic hybrids is located within this conserved region.

To determine the biological relevance of this conserved sequence that results in a DHS in somatic cells we cloned several regions of XIST into the pGL4 series of plasmids to assay promoter and enhancer activity by monitoring luciferase reporter activity after transient transfection into HT1080 somatic cells (Figure 4). We cloned three $\sim 700 \mathrm{bp}$ regions of the XIST promoter region (named $-3,-2,-1$ ) as well as a 1,087 bp region at the - 65 DHS site in both orientations. There was a notable orientation bias for regions around the XIST promoter, and in fact -3 could not be cloned in one orientation. As pGL4.10 lacks a minimal promoter, assaying luciferase activity monitors promoter activity; while pGL4.23 contains a minimal promoter and therefore monitors enhancer activity. In both assays the -65 region showed significant activity, when cloned in both orientations. Thus, like many of the mouse regulatory regions, the -65 DHS seems to have bi-directional promoter and enhancer activity.

\section{Discussion}

$\mathrm{X}$-chromosome inactivation in both humans and mice requires the presence in cis of the $\mathrm{X}$-inactivation center, and the XIST/Xist gene contained therein. Interestingly, the XIST gene appears to have evolved in eutherians from a protein-coding gene, $\operatorname{Lnx} 3$ [31], and while critical regions such as the $5^{\prime} \mathrm{A}$ repeats required for silencing are conserved [19,35], other regions of XIST are more variable amongst the eutheria [36]. Extensive studies in mouse models have defined a wide variety of regulatory elements for Xist including Tsix, DXPas 34 and Xite. These elements are all located 3' to Xist, between Xist and the adjacent testes-specific Ts $x$ gene. In humans TSX is a non-expressed pseudogene, and the blocks of sequence conservation previously reported between humans and mice 3' to XIST are ancestral TSX exons $[31,32]$. The human TSIX region lacks an equivalent to the mouse CpG island that was shown to be essential for function of Tsix $[13,32,37]$. Other significant differences between mouse and human Tsix/TSIX include a lower level of human TSIX transcription and termination of human TSIX prior to the XIST promoter [24,32], while antisense transcription across the mouse Xist promoter region is necessary for antisense function [38]. In addition, Migeon et al. (2002), using RNA FISH for cellular localization of transcripts, showed that human TSIX transcripts are co-expressed with XIST from the inactive $\mathrm{X}$ throughout human embryonic development, 
Promoter - pGL4.10

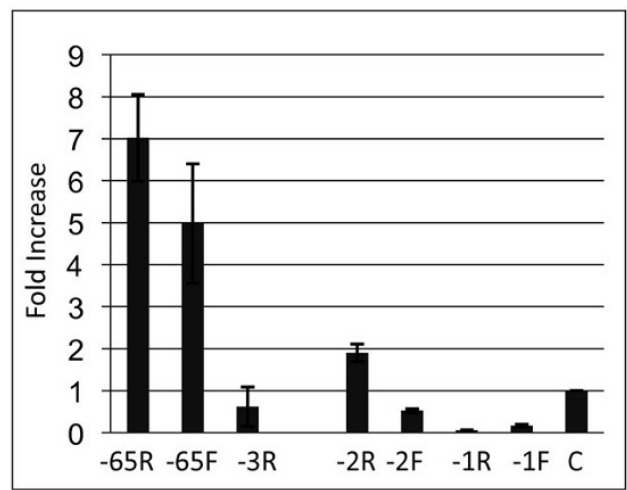

Enhancer - pGL4.23

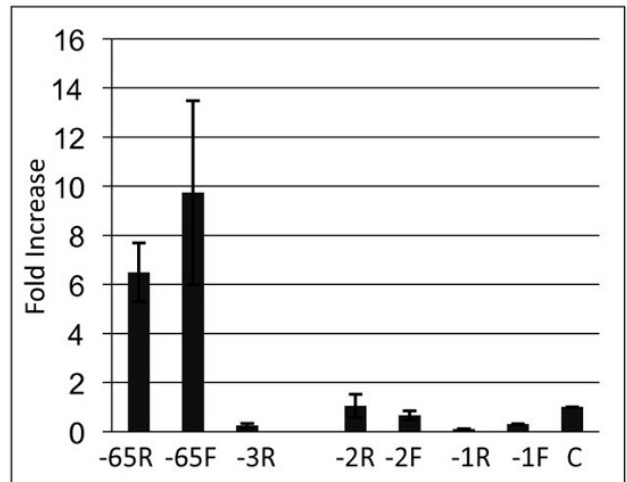

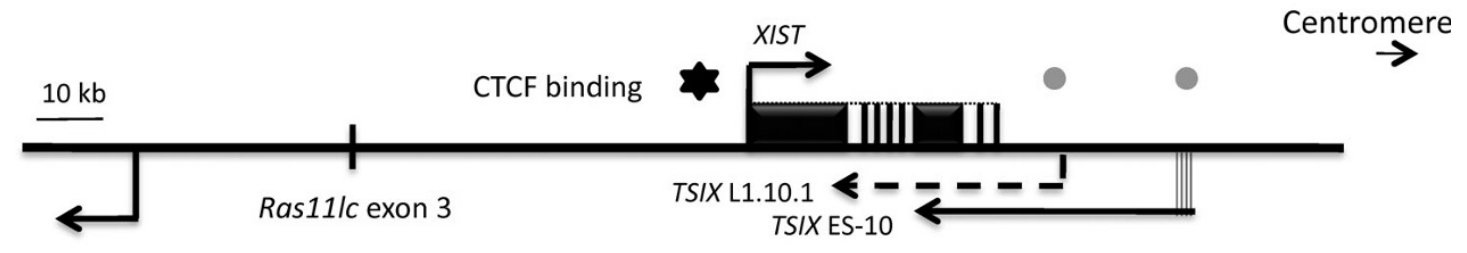

JPX/ENOX
-65 HS site $\Delta$
$-3,-2,-1$ kb HS sites $\Delta$
ES-10 3' HS site

Figure 4 Dual luciferase reporter assays examining promoter and enhancer activities for DNA fragments containing HS site. The pGL4.10 vector, which contains the promoterless synthetic firefly luc2, was used in the promoter assay (left). The pGL4.23 vector, which contains the synthetic firefly luc2 driven by a minimal promoter, was used in the enhancer assay (right). The histograms show a summary of the ratio of luciferase activity (adjusted by dividing the firefly luciferase with the control Renilla luciferase) for each insert (from the HS sites shown in lower panel) relative to the luciferase activity for pGL4.10 or pGL4.23. Each fragment was tested in triplicate and experiments were carried out three times independently. Error bars represent the standard deviations of three trials. While fragments upstream of the XIST promoter containing HS sites showed background luciferase activity, fragment - 65 displayed five fold and seven fold increases in promoter activity and ten fold and six fold increases in enhancer activity in the XIST and antisense orientation, respectively.

suggesting that this antisense is unable to repress XIST [22] leading to the argument that Tsix regulation of Xist may be specific to mouse [39].

Upstream of XIST/Xist the adjacent gene is JPX/ $E N O X$, which is conserved in humans and mice [30], although the distance to the JPX CpG island and first exon is larger in humans $(\sim 90 \mathrm{~kb})$ than in mice (less than $10 \mathrm{~kb}$ ) [30]. JPX is a non-coding RNA gene including different repetitive elements in different species, and the promoter of the mouse Jpx gene has been shown to interact with the Xist promoter in undifferentiated ES cells [40]. No sequence conservation between humans and mice is found in the region between Jpx and Xist; however, there is conservation between humans and cows (and also dogs, data not shown), including an exon of the Rasl11c pseudogene [31].

The lack of sequence conservation between human and mouse in the region flanking XIST/Xist, as well as the differences in the TSIX/Tsix transcript, led us to undertake this study to identify potential regulatory elements for XIST by using DHS mapping both downstream and upstream of XIST. Downstream of XIST in the region where most regulatory elements are observed for mouse Xist we find only a single DHS, and this is only observed in undifferentiated mouse ES cells containing a human XIC transgene. While this site mapped close to one of the previously described human TSIX transcription start sites, the presence of the DHS did not correlate with TSIX transcription, and thus we consider it more likely that this DHS is reflective of a developmental event not regulating antisense transcription. As previously reported there is no substantial sequence conservation between cow, human and mouse downstream of XIST [24,30], and dog also fails to show homologous regions (data not shown). In this region downstream of XIST the human sequence is enriched for LTR class repetitive elements, while mouse and dog are enriched in LINE elements. It has been demonstrated that in addition to a cis-regulatory role in XIST regulation, the mouse $T$ six and Xite regulatory elements are also involved in a trans-regulation involving a transitory pairing of homologous $\mathrm{X}$ chromosomes proposed to establish the mutually exclusive choice of the future active and inactive $\mathrm{X}$ chromosomes in females [41]. As 
the human XIC transgene in the ES-10 cells studied is capable of inducing expression of the single Xist gene in these male ES cells [29], it is plausible that the DHS identified in the transgene 3' to XIST is involved in such trans-interactions. There is now genome-wide mapping of DNase I hypersensitive sites [42] as well as histone modifications and CTCF binding sites, which often mark promoters and enhancers $[43,44]$ in a number of cultured cell lines or human CD4+ cells. The genomewide mapping of CTCF sites in somatic cells did not identify any enrichment in the region of this 3' DHS. However, we also did not observe this DHS in somatic cells. Enhancer sequences have been reported to show cell-type specific patterns [45], so this region may contain an enhancer specific to undifferentiated cells.

We found evidence for DHS sites near the transcriptional start site of XIST in both somatic and ES-10 cells. $X I S T$ is expressed in the ES-10 cells prior to differentiation, however it is not expressed in the Xa-containing hybrid cells, thus these sites are observed independent of XIST expression. We did not refine the localization of these sites, as they likely correspond to the minimal XIST promoter and regulatory elements. The minimal mouse promoter has been shown to have a cluster of DHS sites $[46,47]$. In agreement with the previously defined human minimal promoter [48] we detected strong promoter activity in our transient luciferase assay using $1 \mathrm{~kb}$ of DNA surrounding the XIST transcription start site (data not shown). Although a CTCF binding site has previously been defined at $-43 \mathrm{bp}$ of the XIST promoter [49], genome-wide mapping in $\mathrm{CD}^{+} \mathrm{T}$ cells only identified CTCF binding further upstream [43]. This would correspond to our fragment 3 which showed limited promoter or enhancer activity in the 'reverse' orientation, but was unable to be cloned in the 'forward' orientation where it would be aligned with the test promoter in the same orientation it is aligned to XIST in the human genome. Genome-wide mapping of DHS sites identified a DHS site approximately three $\mathrm{kb}$ upstream of the promoter, in the vicinity of the CTCF site, as well as sites further within XIST that our analysis would not have detected [42]. Thus it appears that there is a regulatory element for human XIST $\sim$ three $\mathrm{kb}$ upstream of the XIST promoter which includes CTCF binding sequences.

Further 5 ' to XIST we find a DHS site in a region sharing sequence conservation with cow and dog (data not shown). A DHS site in this region can also be observed in the genome-wide mapping in $\mathrm{CD} 4^{+} \mathrm{T}$ cells, and furthermore genome-wide H3K4me1 enrichment, which is characteristic of enhancers, flanks the site [45]. We refined the location of the DHS to between $73,053,323$ and 73,053,866, while the DHS site identified by the global mapping is slightly proximal at
73,053,237- 73,053,138. This might reflect subtle discrepancies in mapping, or between cell types. The region cloned for subsequent enhancer and promoter activity analysis was 73,054,787 -73,053,643 and would contain the H3K4me1 marked regions [45] and the majority of the region to which our DHS site was mapped, but be just upstream of the DHS site mapped in CD4+ cells [42].

Overall we find fewer regulatory elements in human than have been identified in mice. This could be due to higher repetitive element content in human which made analyzing the whole region challenging. Furthermore, the repetitive elements themselves might harbour regulatory elements. Indeed, the TSIX transcription starts mapped by Migeon et al. were to MER58B, AluY and L2 class repetitive elements [32], and conservation of repetitive elements between the mouse Tsix transcription start and humans was noted by Cohen et al. [15]. While acquisition of repetitive elements may have led to an expansion of the XIC region in humans compared to mice, the conservation upstream of XIST between humans and other eutheria, including homology to an exon of the Rasl gene of chicken [31] suggests that this region was likely lost in rodents.

While many XIST regulatory elements do not appear to be conserved between humans and mice, many of the basic events required for $\mathrm{X}$-chromosome inactivation must be conserved (reviewed in [21]). The 3' DHS site might demarcate a developmental-specific regulatory region that participates in the trans pairing interactions involved in initiation $[17,41]$. It has been proposed that a critical function of TSIX is to partition chromatin domains in the XIC [50]. Perhaps the 5' regulatory regions we have identified are capable of recapitulating such a function in humans. However we did not observe a consistent difference between the active and inactive $\mathrm{X}$ chromosomes for these DHS sites, and genome-wide chromatin mapping in somatic cells does not show evidence for a chromatin domain ending at the -65 DHS. Ultimately testing whether human $\mathrm{X}$ inactivation involves regulatory processes related to those detailed in mouse will require the challenging investigation of human XIST expression during early development. It has been shown that $\mathrm{X}$ chromosome inactivation is initiated in human preimplantation embryos [51]; however, human ES cells have shown considerable variability (e.g. [27]), making mouse ES cells with human XIST transgenes one of the best current models to study regulation of human XIST.

\section{Conclusions}

DNase I hypersensitivity mapping around the human XIST gene has identified fewer candidate regulatory regions than are observed flanking mouse Xist. In 
particular, 3' to XIST only a single, developmental-specific DHS site was observed in undifferentiated mouse ES cells with an integration of the human XIST domain. 5' to XIST a DHS site was identified in a region of sequence conservation amongst non-rodent eutheria. This region showed bi-directional promoter and enhancer activity. The lack of conservation of regulatory elements for XIST lends support to previous conjectures that human TSIX is no longer a functional regulator of XIST.

\section{Methods}

\section{Tissue Culture \& Cell Lines}

ES-10 cells, a derivative of $\mathrm{J} 1$ male mouse embryonic stem cells with a 480-kb human XIC transgene, were generously provided by Dr. B. Migeon and maintained as described [22]. The L1.10.1 transgenic derivative of human male fibrosarcoma cell line HT-1080 was grown as described [19]. Mouse-human somatic cell hybrids t11-4Aaz5 (containing a human $\mathrm{Xi}$ as well as six human autosomes in addition to mouse chromosomes) and t6012 (containing a human $\mathrm{Xa}$ ) were maintained as described [52].

\section{DNase I Hypersensitivity Mapping}

The preparation of nuclei and the DNase I digest were as described [53]. Briefly, cells were harvested and washed twice in ice-cold PBS, then resuspended at $1 \times$ $10^{7}$ cells $/ \mathrm{ml}$ in $10 \mathrm{ml}$ ice-cold sucrose-triton, swelled on ice for 15 minutes, and then homogenized 10 times in a Dounce homogenizer with a B pestle $(7 \mathrm{ml}$, Wheaton). Homogenized cells were transferred to a $15-\mathrm{ml}$ falcon tube and spun at $1,200 \mathrm{rpm}$ for $15 \mathrm{~min}$ at $4^{\circ} \mathrm{C}$ to recover nuclei which were then resuspended in $1.5 \mathrm{ml}$ of ice cold buffer $(50 \mathrm{mM}$ Tris-Cl pH7.9, $100 \mathrm{mM}$ $\mathrm{NaCl}, 3 \mathrm{mM} \mathrm{MgCl}, 1 \mathrm{mM}$ dithiothreitol, $0.2 \mathrm{mM}$ phenymethylsulfonyl fluoride) and aliquoted into seven 1.5 $\mathrm{ml}$ eppendorf tubes $(200 \mu \mathrm{l}$ each). Nuclei were digested with an increasing amount of DNase I $(10 \mathrm{U} / \mu \mathrm{l}$, RNase free, Roche) (i.e. 1/128, 1/64, 1/32, 1/16, 1/8,1/4 U/ $\mu \mathrm{l}$ ) at $37^{\circ} \mathrm{C}$ for 20 minutes. The digestions were stopped and DNA extracted by adding $1 \mathrm{ml}$ DNazol (Invitrogen) following the manufacturer's protocol. DNase I treated DNA was digested with restriction enzymes according to the manufacturer's recommendations and analyzed by Southern blotting with random-primed $\mathrm{P}^{32}$-labelled probes generated by PCR with primers listed in Table 1 [53]. All analyses were repeated at least twice. As the cell lines contain variable proportions of the human genome they showed differences in cross-hybridization. In order to be identified as a DHS site a band could not be visible in the undigested lane and needed to be replicated.

\section{Sequence Comparisons, Plasmid Construction and Luciferase Assay}

For the dot-plot analyses, we used Mulan (http://mulan. dcode.org/[54]). Five DNA fragments of interest were generated by PCR amplification of human genomic DNA from GM01416 for 35 cycles using primers listed in Table 2. PCR fragments were first cloned into pGEM $^{\circ}$-T Easy vector (Promega) via TA cloning prior

Table 1 Primers for probe generation

\begin{tabular}{llll}
\hline Symbol & Size & Name & Sequence $\mathbf{( 5}^{\prime}$ to $\mathbf{3}^{\prime}$ ) \\
\hline 36 & $921 \mathrm{bp}$ & IP368F & CTTGCTCACCAATTGACTCGTAAG \\
& & IP359R & GAGGACGTGTCAAGAAGACACTAGG \\
\hline 45 & $874 \mathrm{bp}$ & IP453F & CATGGGAAAGCAGCAGACTTCT \\
& & IP444R & GGGCCTGAATGTGAGCATAGAT \\
\hline 101 & $1190 \mathrm{bp}$ & IP1011F & GAATAGCTCAACTGCCAGTGTACT \\
& & IP1000R & GGTCCTCAATGTCCTTACAAAGC \\
\hline 86 & $1041 \mathrm{bp}$ & U862F & TGGAGTCCAGTCGTTGGCT \\
& & U873R & ATAATCTTGCTACTGAAGGGGCT \\
\hline 105 & $1209 \mathrm{bp}$ & U1056F & TGCTTGAAGGGTTACTGCTGTC \\
& & U1068R & CTATACAATGCTCCTGTGATTCTAGTGC \\
\hline 117 & $1140 \mathrm{bp}$ & U1179F & CTTCTGCACTCTGCTAAAGTTCTGAC \\
& & U1190R & TCTGTGACTTGGCAAGCCTTC \\
\hline
\end{tabular}

Table 2 Primers for cloning

\begin{tabular}{|c|c|c|}
\hline Fragment Content & Name & Sequence $\left(5^{\prime}\right.$ to $\left.3^{\prime}\right)$ \\
\hline \multirow[t]{2}{*}{ XIST promoter, positive control } & $0 \mathrm{~F}$ & TCGAGCTCCTTGCTCACCAATTGACTCGTAAG \\
\hline & OR & CGGGTACCGAGGACGTGTCAAGAAGACACTAGG \\
\hline \multirow[t]{2}{*}{$1 \mathrm{~kb}$ upstream of XIST promoter } & $-1 \mathrm{~kb} \mathrm{~F}$ & TCGAGCTCCATTTCCACACTTGTAGAAACTTCTAGTAG \\
\hline & $-1 \mathrm{~kb} R$ & CGGGTACCCTTACGAGTCAATTGGTGAGCAAG \\
\hline \multirow[t]{2}{*}{$2 \mathrm{~kb}$ upstream of XIST promoter } & $-2 \mathrm{~kb} \mathrm{~F}$ & TCGAGCTCGAGCCAAGCAGTAGTGAAGGTGA \\
\hline & $-2 \mathrm{~kb} R$ & CGGGTACCGGTTGTCCTGGGTTTCTGTGA \\
\hline \multirow[t]{2}{*}{$3 \mathrm{~kb}$ upstream of XIST promoter } & $-3 \mathrm{~kb} \mathrm{~F}$ & TCGAGCTCCCCCGTGTTCTCTITTGATAAACTAG \\
\hline & $-3 \mathrm{~kb} \mathrm{R}$ & CGGGTACCTCACCTTCACTACTGCTTGGCTC \\
\hline \multirow[t]{2}{*}{$65 \mathrm{~kb}$ upstream of XIST, covers HS 101} & $-65 \mathrm{~kb} \mathrm{~F}$ & TCGAGCTCGTGGAGTACCCTTTCTATCACAACT \\
\hline & $-65 k b$ R & CGGGTACCTGGCTTGACTTCTAGGGTAAAGA \\
\hline
\end{tabular}

* underlined is genomic sequence from NCBI; not underlined is adaptor (i.e. Sacl \&Kpnl sites) 
to insertion into pGL4.10 and pGL4.23 reporter vectors (Promega) upstream of the firefly luciferase gene. The identities of pGL4 clones were confirmed by restriction enzyme digestion and partial sequence analysis. Transient transfection was performed in 24-well plates with $80 \%$ confluent HT1080 cells. $0.8 \mu \mathrm{g}$ of firefly luciferase plasmid (pGL4, Promega) and 80 ng of the Renilla luciferase plasmid (Promega) were co-transfected into cells using $2 \mu \mathrm{l}$ Lipofectamine ${ }^{\mathrm{tw}} 2000$ (Invitrogen). For each transfection assay, the pGL4.13 vector, which contains a promoter/enhancer element, was used as positive control and the pGL4.10 vector, which contains neither promoter nor enhancer, was used as negative control. Transfection of the pGL4.23 vector with a basal promoter also served as a control. After $24 \mathrm{~h}$, cell lysates were prepared from each transfected culture and were analyzed in a 96-well plate luminometer (Perkin Elmer Wallace) according to manufacturer's protocol in the Dual Luciferase Kit (Promega). Each fragment was tested in triplicate, and each experiment was repeated at least three times. To control for transfection efficiency, the ratio of firefly luciferase signal to Renilla luciferase signal was calculated for each transfected sample.

\section{Acknowledgements}

Funding for this study was provided by Canadian Institute of Health Research Operating Grant MOP-13690. The ES-10 cells were generously provided by Dr. B. Migeon. The authors would like to thank Drs. Hugh Brock and Dixie Mager for helpful suggestions and Jakub Minks and other members of the Brown laboratory for advice and critical review of the manuscript.

\section{Authors' contributions}

SC carried out the molecular studies and drafted the manuscript. CB participated in the design of the study and revised the manuscript. Both authors read and approved the final manuscript.

Received: 28 October 2009

Accepted: 8 March 2010 Published: 8 March 2010

\section{References}

1. Russell LB: Mammalian X-chromosome action: inactivation limited in spread and in region of origin. Science 1963, 140:976-978.

2. Brown CJ, Ballabio A, Rupert JL, Lafreniere RG, Grompe M, Tonlorenzi R, Willard HF: A gene from the region of the human $\mathrm{X}$ inactivation centre is expressed exclusively from the inactive $\mathbf{X}$ chromosome. Nature 1991, 349:38-44

3. Brockdorff N, Ashworth A, Kay GF, McCabe VM, Norris DP, Cooper PJ, Swift S, Rastan S: The product of the mouse Xist gene is a $15 \mathrm{~kb}$ inactive $\mathrm{X}$-specific transcript containing no conserved ORF and located in the nucleus. Cell 1992, 71:515-526.

4. Brown CJ, Hendrich BD, Rupert JL, Lafreniere RG, Xing Y, Lawrence J, Willard HF: The human XIST gene: analysis of a $17 \mathrm{~kb}$ inactive X-specific RNA that contains conserved repeats and is highly localized within the nucleus. Cell 1992, 71:527-542.

5. Penny GD, Kay GF, Sheardown SA, Rastan S, Brockdorff N: Requirement for Xist in X chromosome inactivation. Nature 1996, 379:131-137.

6. Marahrens Y, Panning B, Dausman J, Strauss W, Jaenisch R: Xist-deficient mice are defective in dosage compensation but not spermatogenesis. Genes \& Dev 1997, 11:156-166.
7. Lee JT, Strauss WM, Dausman JA, Jaenisch R: A $450 \mathrm{~kb}$ transgene displays properties of the mammalian X-inactivation center. Cell 1996, 86:83-94.

8. Rastan S, Robertson EJ: X-chromosome deletions in embryo-derived (EK) cell lines associated with lack of X-chromosome inactivation. J Embryol Exp Morph 1985, 90:379-388.

9. Lee JT, Davidow LS, Warshawsky D: Tsix, a gene antisense to Xist at the Xinactivation center. Nat Genet 1999, 21:400-404.

10. Ogawa $Y$, Lee JT: Xite, $X$-inactivation intergenic transcription elements that regulate the probability of choice. Mol Cell 2003, 11:731-743.

11. Mise N, Goto Y, Nakajima N, Takagi N: Molecular cloning of antisense transcripts of the mouse Xist gene. Biochem Biophys Res Comm 1999, 258:537-541.

12. Stavropoulos N, Lu N, Lee JT: A functional role for Tsix transcription in blocking Xist RNA accumulation but not in X-chromosome choice. Proc Natl Acad Sci USA 2001, 98:10232-10237.

13. Lee JT, Lu N: Targeted mutagenesis of Tsix leads to nonrandom X inactivation. Cell 1999, 99:47-57.

14. Debrand E, Chureau C, Arnaud D, Avner P, Heard E: Functional analysis of the DXPas34 locus, a 3' regulator of Xist expression. Mol Cell Biol 1999, 19:8513-8525.

15. Cohen DE, Davidow LS, Erwin JA, Xu N, Warshawsky D, Lee JT: The DXPas 34 repeat regulates random and imprinted $\mathrm{X}$ inactivation. Dev Cell 2007, 12:57-71.

16. Xu N, Donohoe ME, Silva SS, Lee JT: Evidence that homologous Xchromosome pairing requires transcription and Ctcf protein. Nat Genet 2007, 39:1390-1396.

17. Bacher CP, Guggiari M, Brors B, Augui S, Clerc P, Avner P, Eils R, Heard E: Transient colocalization of $X$-inactivation centres accompanies the initiation of $X$ inactivation. Nat Cell Biol 2006, 8:293-299.

18. Wutz $A$, Jaenisch $R$ : $A$ shift from reversible to irreversible $X$ inactivation is triggered during ES cell differentiation. Mol Cell 2000, 5:695-705.

19. Chow JC, Hall LL, Baldry SE, Thorogood NP, Lawrence JB, Brown CJ: Inducible XIST-dependent X-chromosome inactivation in human somatic cells is reversible. Proc Natl Acad Sci USA 2007, 104:10104-10109.

20. Takagi N, Sasaki M: Preferential inactivation of the paternally derived X chromosome in the extraembryonic membranes of the mouse. Nature 1975, 256:640-642.

21. Migeon BR: $\mathbf{X}$ chromosome inactivation: theme and variations. Cytogenet Genome Res 2002, 99:8-16.

22. Migeon BR, Lee $\mathrm{CH}$, Chowdury AK, Carpenter $\mathrm{H}$ : Species differences in TSIX/Tsix reveal the roles of these genes in X-chromosome inactivation. Am J Hum Genet 2002, 71:286-293.

23. Shibata S, Lee JT: Characterization and quantitation of differential Tsix transcripts: implications for Tsix function. Hum Mol Genet 2003, 12:125-136.

24. Chow JC, Hall LL, Clemson CM, Lawrence JB, Brown CJ: Characterization of expression at the human XIST locus in somatic, embryonal carcinoma, and transgenic cell lines. Genomics 2003, 82:309-322.

25. Migeon BR, Winter H, Kazi E, Chowdhury AK, Hughes A, Haisley-Royster C, Morrison $H$, Jeppesen P: Low-copy-number human transgene is recognized as an $X$ inactivation center in mouse ES cells, but fails to induce cis-inactivation in chimeric mice. Genomics 2001, 71:156-162.

26. Chow JC, Hall LL, Lawrence JB, Brown CJ: Ectopic XIST transcripts in human somatic cells show variable expression and localization. Cytogenet Genome Res 2002, 99:92-98.

27. Hall LL, Byron M, Butler J, Becker KA, Nelson A, Amit M, Itskovitz-Eldor J, Stein J, Stein G, Ware C, Lawrence JB: X-inactivation reveals epigenetic anomalies in most hESC but identifies sublines that initiate as expected. J Cell Physiol 2008, 216:445-452.

28. Heard E, Mongelard F, Arnaud D, Chureau C, Vourc'h C, Avner P: Human XIST yeast artificial chromosome transgenes show partial $X$ inactivation center function in mouse embryonic stem cells. Proc Natl Acad Sci USA 1999, 96:6841-6846.

29. Migeon BR, Kazi E, Haisley-Royster C, Hu J, Reeves R, Call L, Lawler A, Moore CS, Morrison $\mathrm{H}$, Jeppesen P: Human X inactivation center induces random $\mathrm{X}$ chromosome inactivation in male transgenic mice. Genomics 1999, 59:113-121.

30. Chureau C, Prissette M, Bourdet A, Barbe V, Cattolico L, Jones L, Eggen A, Avner $P$, Duret $L$ : Comparative sequence analysis of the $X$-inactivation 
center region in mouse, human and bovine. Genome Res 2002, 12:894-908.

31. Duret L, Chureau C, Samain S, Weissenbach J, Avner P: The Xist RNA gene evolved in eutherians by pseudogenization of a protein-coding gene. Science 2006, 312:1653-1655.

32. Migeon BR, Chowdury AK, Dunston JA, McIntosh I: Identification of TSIX, encoding an RNA antisense to human XIST, reveals differences from its murine counterpart: implications for $\mathrm{X}$ inactivation. Am J Hum Genet 2001, 69:951-960.

33. Elgin SCR: DNAase I-hypersensitive sites of chromatin. Cell 1981, 27:413-415.

34. RepeatMasker Open-3.0. http://www.repeatmasker.org/cgi-bin/ WEBRepeatMasker.

35. Wutz A, Rasmussen TP, Jaenisch R: Chromosomal silencing and localization are mediated by different domains of Xist RNA. Nat Genet 2002, 30:167-174.

36. Yen ZC, Meyer IM, Karalic S, Brown CJ: A cross-species comparison of Xchromosome inactivation in Eutheria. Genomics 2007, 90:453-463.

37. Lee JT: Homozygous Tsix mutant mice reveal a sex-ratio distortion and revert to random X-inactivation. Nat Genet 2002, 32:195-200.

38. Ohhata T, Hoki Y, Sasaki H, Sado T: Crucial role of antisense transcription across the Xist promoter in Tsix-mediated Xist chromatin modification. Development 2008, 135:227-235.

39. Migeon BR: Is Tsix repression of Xist specific to mouse?. Nat Genet 2003, 33:337.

40. Tsai $C L$, Rowntree RK, Cohen DE, Lee JT: Higher order chromatin structure at the X-inactivation center via looping DNA. Dev Biol 2008, 319:416-425.

41. Xu N, Tsai CL, Lee JT: Transient homologous chromosome pairing marks the onset of X inactivation. Science 2006, 311:1149-1152.

42. Boyle AP, Davis S, Shulha HP, Meltzer P, Margulies EH, Weng Z, Furey TS, Crawford GE: High-resolution mapping and characterization of open chromatin across the genome. Cell 2008, 132:311-322.

43. Barski A, Cuddapah S, Cui K, Roh TY, Schones DE, Wang Z, Wei G, Chepelev I, Zhao K: High-resolution profiling of histone methylations in the human genome. Cell 2007, 129:823-837.

44. Heintzman ND, Stuart RK, Hon G, Fu Y, Ching CW, Hawkins RD, Barrera LO, Van Calcar S, Qu C, Ching KA, et al: Distinct and predictive chromatin signatures of transcriptional promoters and enhancers in the human genome. Nat Genet 2007, 39:311-318.

45. Heintzman ND, Hon GC, Hawkins RD, Kheradpour P, Stark A, Harp LF, Ye Z, Lee LK, Stuart RK, Ching CW, et al: Histone modifications at human enhancers reflect global cell-type-specific gene expression. Nature 2009, 459:108-112.

46. Sheardown SA, Newall AET, Norris DP, Rastan S, Brockdorff N: Regulatory elements in the minimal promoter region of the mouse Xist gene. Gene 1997, 203:159-168.

47. Newall AE, Duthie S, Formstone E, Nesterova T, Alexiou M, Johnston C, Caparros ML, Brockdorff N: Primary non-random X inactivation associated with disruption of Xist promoter regulation. Hum Mol Genet 2001, 10:581-589.

48. Hendrich $B D$, Plenge RM, Willard HF: Identification and characterization of the human XIST gene promoter: implications for models of $X$ chromosome inactivation. Nucl Acids Res 1997, 25:2661-2671

49. Pugacheva EM, Tiwari VK, Abdullaev Z, Vostrov AA, Flanagan PT, Quitschke WW, Loukinov DI, Ohlsson R, Lobanenkov W: Familial cases of point mutations in the XIST promoter reveal a correlation between CTCF binding and pre-emptive choices of $\mathrm{X}$ chromosome inactivation. Hum Mol Genet 2005, 14:953-965.

50. Navarro P, Chantalat S, Foglio M, Chureau C, Vigneau S, Clerc P, Avner P, Rougeulle C: A role for non-coding Tsix transcription in partitioning chromatin domains within the mouse X-inactivation centre. Epigenetics Chromatin 2009, 2:8.

51. Berg van den IM, Laven JS, Stevens M, Jonkers I, Galjaard RJ, Gribnau J, van Doorninck $\mathrm{JH}: \mathrm{X}$ chromosome inactivation is initiated in human preimplantation embryos. Am J Hum Genet 2009, 84:771-779.

52. Brown CJ, Powers VE, Monroe DM, Sheinin R, Willard HF: A gene on the short arm of the human $X$ chromosome complements the murine tsA1S9 DNA synthesis mutation. Som Cell Mol Genet 1989, 15:173-178.

53. Sambrook J, Fritsch EF, Maniatis T: Molecular Cloning: A laboratory manual. Cold Spring Harbor: Cold Spring Harbor Laboratory 1989, 2.
54. Ovcharenko I, Loots GG, Giardine BM, Hou M, Ma J, Hardison RC, Stubbs L, Miller W: Mulan: multiple-sequence local alignment and visualization for studying function and evolution. Genome Res 2005, 15:184-194.

55. Stavropoulos N, Rowntree RK, Lee JT: Identification of developmentally specific enhancers for Tsix in the regulation of $X$ chromosome inactivation. Mol Cell Biol 2005, 25:2757-2769.

doi:10.1186/1471-2199-11-20

Cite this article as: Chang and Brown: Identification of regulatory elements flanking human XIST reveals species differences. $B M C$ Molecular Biology 2010 11:20.

\section{Submit your next manuscript to BioMed Central and take full advantage of:}

- Convenient online submission

- Thorough peer review

- No space constraints or color figure charges

- Immediate publication on acceptance

- Inclusion in PubMed, CAS, Scopus and Google Scholar

- Research which is freely available for redistribution

Submit your manuscript at www.biomedcentral com/submit
C Biomed Central 